Article Type: Articles

Running head: Weather, consumers, and marsh recovery

\title{
Weather fluctuations affect the impact of consumers on vegetation recovery following a catastrophic die-off
}

Qiang $\mathrm{He}^{1,2,{ }^{*}}$, Brian R. Silliman ${ }^{2}$, Johan van de Koppel ${ }^{3,4}$, and Baoshan Cui ${ }^{5}$

1 Coastal Ecology Lab, MOE Key Laboratory of Biodiversity Science and Ecological Engineering, Fudan

University, 2005 Songhu Road, Shanghai 200438, China

2 Division of Marine Science and Conservation, Nicholas School of the Environment, Duke University,

135 Duke Marine Lab Road, Beaufort, NC 28516, USA

3 Spatial Ecology Department, Royal Netherlands Institute for Sea Research (NIOZ), 4401NT 7

Yerseke, The Netherlands

4 Conservation Ecology Group, Groningen Institute for Evolutionary Life Sciences, University of

Groningen, 9700 CC Groningen, The Netherlands

This article has been accepted for publication and undergone full peer review but has not been through the copyediting, typesetting, pagination and proofreading process, which may lead to differences between this version and the Version of Record. Please cite this article as doi:

10.1002/ecy.2559

This article is protected by copyright. All rights reserved. 
5 School of Environment, State Key Laboratory of Water Environment Simulation, Beijing Normal

University, Beijing 100875, China

* Corresponding author. Qiang He: he_qiang@hotmail.com

Article Type: Articles

Abstract: Prolonged droughts exacerbated by climate change have been widely documented to interact with consumers to decimate vegetation in many ecosystems. Although climate change is also increasing within-year variation in precipitation and temperature, how weather fluctuations affect the impact of consumers on vegetation processes remains poorly understood. In a salt marsh that has recently experienced drought-associated vegetation die-off, we investigated how top-down control of plant recovery by a prominent salt marsh grazer varies with weather. Our results showed that grazing-driven plant mortality varied strongly with weather in spring, with intense grazing occurring during cool, wet days immediately following rain. Intense grazing in cool, wet days across the generally dry, spring season had a strong impact that eliminated plant seedlings that could otherwise have become tolerant of grazing in the following summer, thereby restricting vegetation recovery and contributing to the persistence of an unvegetated salt barren state. Thus, weather fluctuations can modulate the impact of consumers on vegetation recovery, a fundamental process underlying the fate of ecosystems after disturbances. A multi-timescale perspective on top-down

This article is protected by copyright. All rights reserved. 
control that combines the impact of short-term fluctuations in weather and that of long-term variation in mean climate can not only help understand ecosystem dynamics in an increasingly variable climate, but may also inform conservation strategies or recovery plans for ecosystems that are already lost to climate change.

Key words: coastal wetlands, drought, herbivory, multiple timescales, rainfall variation, temporal ecology, top-down control, salt marsh

\section{INTRODUCTION}

Climate change is projected to not only result in changes in mean climate but also to exacerbate temporal variation in precipitation and temperature (Coumou and Rahmstorf 2012, Thompson et al. 2013, Garcia et al. 2014), pressing the need for a better understanding of temporal variation in ecosystem processes (Wolkovich et al. 2014). At broad timescales, the importance of long-term studies in climate change ecology has been generally recognized, and an increasing number of multi-year or multi-decade studies on the impacts of seasonal or annual variation in mean climate have been conducted (e.g., Greenville et al. 2012, Pascual et al. 2015, He et al. 2017). Many key ecological processes, however, are operating at basal, fine timescales (Hastings 2004), and are highly responsive to short-term, even daily variation in temperature and precipitation (Touchon and Warkentin 2009, Wright et al. 2015, CaraDonna et al. 2017). Understanding variation in such ecological processes would thus require studies at fine timescales (Wolkovich et al. 2014). Such studies are necessary to distinguish the importance of high-order climatic factors (e.g., discrete rain events and coldest day of a year), and can also help to understand critical ecological processes, such 
as sudden, catastrophic ecosystem die-offs and their recovery (Scheffer et al. 2009, Carpenter et al. 2011).

A fine-timescale perspective is especially important for a deeper understanding of the impacts of consumers on vegetation dynamics in the face of increasing temporal variation in climate. It has been widely documented that during climatic anomalies consumer pressure can be amplified and interact with climatic stress to impair vegetation (e.g., trees and grasses) in ecosystems (Silliman et al. 2013). Such consumer-climate interactive processes have been observed to generate massive vegetation die-offs in all Earth's biomes (McDowell et al. 2011, He et al. 2017). Consumer-climate interactive processes can also affect or suppress vegetation recovery following initial die-offs, altering the trajectory of ecosystem changes at longer timescales (Angelini and Silliman 2012, He et al. 2017). In either case, although the roles of seasonal, annual, or decadal variation in climate in mediating the impacts of consumers (Brown and Shine 2007, Pascual et al. 2015, He et al. 2017) have been repeatedly reported, how fluctuations in weather affect the impact of consumers on vegetation dynamics is relatively less studied, despite the fact that many consumers are highly sensitive to variation in precipitation and temperature (Touchon and Warkentin 2009).

Here we provide a multi-timescale investigation into the impact of consumers on salt marsh vegetation recovery following a large-scale die-off event. Vegetation die-off has been reported to occur under climate change across a global range of coastal wetlands (Osland et al. 2014, Duke et al. 2017, Gabler et al. 2017), which can be exacerbated by strong top-down effects of consumers, such as snails, crabs, and geese (He et al. 2017). The 1999-2001 drought in southeastern US, for example, were found to intensify snail grazing on salt marsh vegetation, which contributed to 
the die-off of salt marshes across $1500 \mathrm{~km}$ of coastline (Silliman et al. 2005). More recently, a severe spring drought that hit temperate China in 2011 acted in combination with plant-killing crabs to eliminate salt marsh vegetation (He et al. 2017; Fig. 1a). This drought has been further found to have a legacy effect (sensu Anderegg et al. 2013) - after the drought ended, grazing by crabs (Fig. 1b) concentrated on remaining plant patches and continued to suppress vegetation recovery for years, leading to the formation of persistent salt barrens devoid of vegetation (He et al. 2017). Strong grazing impacts in dry seasons/years are apparently contrary to the fact that many animals in coastal habitats are often inactive when it is dry (to avoid desiccation stress; Bertness 1981, Sanford 2002). Resolving this paradox would need an understanding of how grazing impacts vary with weather condition at fine timescales. In all the past studies, however, the impact of grazers was simply estimated as an annually aggregated impact at the end of the growing season, and a fine-timescale understanding of its variation with weather is not available.

In this study, using a series of grazer exclusion experiments conducted in different periods of rains scattered over a generally dry, spring season, we first examined how fluctuations in weather affect the impact of grazing crabs, a prominent consumer in many coastal habitats (He and Silliman 2016), on salt marsh plant reestablishment in die-off areas following the 2011 China drought. To assess the relative importance of spring grazing vs. summer grazing in vegetation recovery, we further conducted grazer exclusion experiments and compared the strength of grazing impact between spring and summer seasons. Specifically, we tested the following hypotheses: 1 ) the effect of grazing on salt marsh plant establishment in die-off areas strongly varies with fluctuations in weather, and is stronger on rainy days (when salt marsh grazers are supposed to be more active) 
than during dry periods (when salt marsh grazers often stay in shelters [e.g., burrows] to avoid desiccation stress); 2) the cumulative impact of grazing over rainy days across the generally dry, spring season (when plant seedlings are establishing) more critically suppresses plant survival than across the summer season (when plants become established and tolerant of grazing). Our study tests how top-down control of vegetation recovery by consumers varies with fluctuations in weather and how a fine-timescale perspective can help understand variation in the impact of consumers on vegetation dynamics with climate at longer, seasonal and annual timescales.

\section{METHODS}

\section{Study site}

Field work was conducted in a high marsh in the Yellow River Delta $\left(37^{\circ} 46^{\prime} \mathrm{N}, 119^{\circ} 09^{\prime} \mathrm{E}\right)$ a protected salt marsh in temperate coastal China (He et al. 2015). The study site has a temperate monsoonal climate, with a long-term mean annual precipitation of $597 \mathrm{~mm}$ and an annual mean temperature of $12.9^{\circ} \mathrm{C}$ (Li et al. 2009). Soil salinity varies greatly, depending on factors including marsh elevation and precipitation, and it can be twice higher in drought than in non-drought years (detailed in He et al. 2017). The vegetation is dominated by Suaeda salsa (L.) Pall., an annual succulent known to be highly tolerant of salinity and water stresses (He et al. 2015, 2017). Despite its high salinity and water stress tolerances, $S$. salsa is susceptible to grazing by the herbivorous crab Helice tientsinensis Rathbun that is abundant in the salt marsh (He et al. 2015). Sueada salsa vegetation at our study site dramatically declined following an extreme drought in spring 2011 (see 
Text S1 in He et al. 2017 for a brief historical perspective regarding these die-off events). While the drought itself had only moderate effects on S. salsa plants, grazing by crabs eliminated drought-weakened plants, and continued to suppress vegetation recovery for years after the drought ended. As a result, the current state of our study site is generally an expansive salt flat (Fig. 1a). Although crab abundance also declined following the drought, some crabs (on average 2-3 burrows $/ \mathrm{m}^{2}$ ) were able to persist in the bare flat. This effect of grazing in restricting vegetation recovery has been shown to be generally consistent across multiple sites in northern China (He et al. 2017).

Our study was mainly conducted between May and August 2013, two years after the 2011 drought ended (He et al. 2017). During the study period, total precipitation over the dry (May-June) and wet (July-August) seasons (Fig. 2a) was 119.3 and $553.5 \mathrm{~mm}$, mean daily temperature was $21.9 \pm 3.8$ and $27.2 \pm 2.2(\mathrm{SD}){ }^{\circ} \mathrm{C}$, and mean daily relative humidity was $60 \pm 13 \%$ and $75 \pm 10 \%$, respectively. Daily precipitation data were collected using a rain gauge (WatchDog 1120 Data-Logging Rain Gauge; Spectrum Technologies, Inc., Aurora, IL, USA) installed $1.5 \mathrm{~m}$ above the ground and $\sim 300 \mathrm{~m}$ east of our study site. Daily mean temperature and relative humidity data (Fig. $2 \mathrm{~b})$ at the nearest weather station $\left(37.6236^{\circ} \mathrm{N}, 119.0620^{\circ} \mathrm{E}\right)$ were obtained from National Centers for Environmental Prediction (http://globalweather.tamu.edu/). The weather station, $19 \mathrm{~km}$ south of our study site, was also located on the coast. In contrast to precipitation that may vary considerably spatially, temperature and relative humidity are more spatially homogeneous (Hubbard 1994). Additionally, high marshes at our study site are seldom flooded by tides, especially in late 
spring and summer when winds from the south prevent tidal waters from reaching upper elevations of the north-facing salt marsh.

\section{Variation with weather}

To examine how the impact of grazing on plant establishment in vegetation die-off areas varies with weather, we conducted a S. salsa transplant and grazing exclusion experiment (Fig. 2a), where $60 \mathrm{~S}$. salsa transplants were randomly assigned to spring grazing treatments ( $n=40$ in total, ten of which were randomly exposed to grazing in each of four different periods of rain; detailed below), summer grazing treatments ( $n=10$; see the section "Seasonal variation: Short-term effects"), and permanent grazing exclusion treatments $(n=10)$. Suaeda salsa transplants were soil blocks (10 cm diameter, $10 \mathrm{~cm}$ depth; containing > 20 S. salsa seedlings), excavated in an adjacent (< $100 \mathrm{~m}$ ) vegetated area, and translocated into the die-off area (spaced > $2 \mathrm{~m}$ apart) in mid-May 2013. We used transplants, as S. salsa natural recruitment in the die-off area was sparse and was often damaged by crabs (Fig. 1) and transplants are widely used in restoration efforts to recover vegetation in salt marshes (see He et al. 2017).

All the transplants were initially covered with a grazing exclusion cage $(40 \mathrm{~cm}$ tall) made of galvanized hardware mesh (7-mm mesh size) and held by a PVC pipe. The 10 transplants assigned to permanent grazing exclusion treatments were also covered with a belowground grazing exclusion cage (10 cm deep) to limit crab access through burrowing that could occur over a long period (note that we did not include cage controls here; our prior experiments at the same study site found no 
experimental artifact of cages of the same design; He et al. 2017). Then the surviving plant seedlings in each transplant during the first week were thinned to 10 individuals of similar size (3-6 cm high) for standardization. Ten of the 40 transplants assigned to spring grazing treatments had their aboveground grazing exclusion cages removed on May 21 (three days after a rain ended; hereafter the first post-rain experiment), May 25 (the day before a forecasted rain; hereafter the during-rain experiment), May 29 (two days after the forecasted rain ended; hereafter the second post-rain experiment), and June 4 (after a one-week period without rain; hereafter the dry period experiment), respectively. The number of surviving seedlings in each transplant was then counted two days and four days later. We used survival as the response variable, as (1) no new emergence was observed, and (2) crabs often ate the entire aboveground part of small S. salsa seedlings (Fig. 1b; He et al. 2015).

To examine if the impact of grazing on plant survival varies between different periods of rain, we first computed relative increases in plant mortality in grazing treatments vs. permanent grazing exclusion treatments as $100-N_{\mathrm{C}} * 100 / N_{\mathrm{E}}$, where $N_{\mathrm{C}}$ is the number of plant survivors in a grazing treatment and $N_{\mathrm{E}}$ is the average number of plant survivors in the ten permanent grazing exclusion treatments. Differences in the impact of grazing among different periods of rain were examined using nonparametric multiple comparisons (Dunn's test with joint rankings) and Tukey HSD multiple comparisons for the two-day and four-day assessments, respectively (Borenstein et al. 2009). In addition, we used least squares regressions to test if the impact of grazing in different periods of rain varies as a continuous function of daily-averaged temperature and relative humidity.

This article is protected by copyright. All rights reserved. 
All the statistical analyses in this manuscript were conducted using JMP 10 (SAS Institute, Cary, NC, USA).

\section{Seasonal variation: Short-term effects}

To assess the relative importance of spring grazing vs. summer grazing in vegetation

recovery in die-off areas, we first conducted short-term experiments testing impacts of crab grazing in spring (June 4-18) and summer (July 17-August 5) periods, respectively, in 2013 (Fig. 2a). To replicate the treatment "season" in another year, we carried out similar S. salsa transplant and grazing exclusion experiments in spring and summer periods, respectively, in 2018.

For the spring experiment in 2013 , we continued to monitor the number of plant survivors in each of the transplants in the dry-period experiment described above (initially released to crab grazing on June 4) every two to four days until all plants in these treatments vanished on June 18. For the summer experiment, the 10 transplants assigned to summer grazing treatments had their cages removed on July 17 . We then counted the number of plant survivors in each of these transplants, as well as in each of the ten permanent grazing exclusion treatments, periodically for four times until August 5 . In both experiments, we also counted the total number of leaves in each transplant and measured the height of three randomly-selected plants in each transplant while the number of plant survivors was counted.

This article is protected by copyright. All rights reserved. 
For the 2018 S. salsa transplant and grazing exclusion experiments, S. salsa transplants ( $n=$ 24 in total) and crab grazing treatments were established in May, using the same procedure as described above for the 2013 experiments, except that (1) the spring and summer grazing experiments were both run for ten days (May 24-June 3 and July 17-27, respectively) and (2) in both experiments each treatment was replicated eight times.

To test if the impact of grazing on plant survival differs between spring and summer seasons in each year, we first computed relative increases in plant mortality in grazing treatments vs. permanent grazing exclusion treatments in each season using the equation given above, and then divided these data by experimental duration (14 and 19 days for the spring and summer season experiments in 2013, and 10 and 10 days in 2018, respectively) to estimate daily-averaged effects of grazing. Similarly, for the 2013 experiments, we estimated daily-averaged number of plant leaves lost to grazing as the difference between grazing and permanent grazing exclusion treatments divided by experimental duration. To test for differences between spring and summer seasons, data of daily-averaged impacts of grazing on plant mortality and plant height were analyzed using Wilcoxon tests, and data of number of leaves lost to grazing $\left([x+4]^{\wedge} 2\right.$ transformed) were analyzed using one-way ANOVAs. Since the summer experiment in 2013 had much fewer plants that died of grazing but lasted for a longer period than did the spring experiment (see Results), this spring vs. summer comparison was conservative.

This article is protected by copyright. All rights reserved. 


\section{Seasonal variation: Season-long effects}

To examine the cumulative impact of grazing on plant establishment in vegetation die-off areas across the entire spring vs. summer, we further conducted a S. salsa transplant and grazing exclusion experiment in 2013 (Fig. 2a). In this experiment, S. salsa transplants ( $n=16$ in total) were randomly assigned to grazing exclusion treatments $(n=8)$ and control treatments $(n=8)$, respectively, in the spring; and then half of the 8 transplants assigned to grazing exclusion treatments in the spring were exposed to grazing in the following summer. The $S$. salsa transplants were soil blocks ( $15 \mathrm{~cm}$ diameter, $10 \mathrm{~cm}$ depth) containing naturally dense $S$. salsa seedlings excavated from a well-vegetated area, and two of the soil blocks were translocated into each of eight $1 \times 1 \mathrm{~m}$ plots (spaced $>2 \mathrm{~m}$ apart) in the die-off area in early May. Given the longer duration of these experiments, S. salsa transplants of a larger size were used here than in the above short-term experiments. One of the two transplants in each plot was initially assigned to grazing exclusion and control treatments, respectively.

Transplants assigned to grazing exclusion treatments were caged belowground $(15 \mathrm{~cm}$ diameter, $20 \mathrm{~cm}$ depth) and aboveground using plastic mesh $(15 \times 15 \times 30 \mathrm{~cm})$ held together by iron-bar frames, while those assigned to control treatments were uncaged and open to crab grazing. At the end of the spring season in late June, the number of plants in each transplant was counted.

Then we randomly selected four transplants assigned to grazing exclusion treatments in the spring, and removed their cages to examine the impact of grazing in the summer. In late August, the number of plants in each transplant was counted again, and plants in each transplant were harvested, oven-dried at $60^{\circ} \mathrm{C}$ for $48 \mathrm{~h}$, and weighed.

This article is protected by copyright. All rights reserved. 
Differences in the number of plants per transplant between different grazing treatments were analyzed with a paired-sample Wilcoxon test (spring) and a Wilcoxon test (summer), respectively. To more straightforwardly compare the strength of the grazing impact between spring and summer seasons, we further computed relative differences in the number of plants in grazing exclusion vs. control treatments in each season similarly using the equation given above (except that for the spring experiment, $N_{\mathrm{E}}$ is the number of plants in a paired grazing exclusion treatment). These data were then analyzed for differences between seasons using a Wilcoxon test (to address the issue of unequal sample size). Additionally, we analyzed differences in plant biomass per transplant and plant biomass per plant survivor (a measure of plant size) between different grazing treatments using one-way ANOVAs.

\section{RESULTS}

\section{Variation with weather}

During the generally dry spring, the impact of grazing on plant survival differed significantly among different periods of rain. Over a two-day period, grazing-driven plant mortality 1 ) was weak in the first post-rain experiment, 2) did not significantly differ from zero in the during-rain experiment, 3) was highest ( 70\%) in the second post-rain experiment, and 4) largely waned in the following dry-period experiment (d.f. $=3, \chi^{2}=16.28, P=0.0010$ ) (Fig. 3a). The results were generally consistent when the impact of grazing was analyzed over a four-day period (d.f. $=3,36, F=7.49, P=$ 0.0005), except that in the during-rain experiment the impact of grazing on plant mortality became 
significant and strong, due to intense grazing over the third and fourth days when the two-day rain ended (Fig. 3a). Despite minimal grazing-driven plant mortality in the dry-period experiment, continuing this experiment over a longer period consistently showed that grazing-driven plant mortality elevated following the first rainfall that this experiment encountered (Fig. 3b). As a result of this intensified grazing pressure, nearly $100 \%$ of plants in transplants open to crab grazing vanished in the following few days.

The strength of the grazing impact was also negatively correlated with temperature. Daily mean temperature was highest in the dry-period experiment and was lowest in the during-rain experiment (Appendix S1: Fig. S1a). Across all the above experiments, the strength of the grazing impact on plant mortality significantly decreased with increasing temperature (Appendix S1: Fig. S2). Although daily mean relative humidity was higher in the during-rain experiment than in the dry-period experiment and the two post-rain experiments (Appendix S1: Fig. S1b), no significant relationship with relative humidity was found (Appendix S1: Fig. S2). These relationships with temperature and relative humidity were consistent when the impact of grazing was analyzed over a two-day period and a four-day period (Appendix S1: Fig. S2).

\section{Seasonal variation: Short-term effects}

In the summer when rain occurred frequently without clear dry and wet periods, the effect of grazing on plant survival was still significant, with $\sim 50 \%$ of plants being killed by crabs over a 19-day period (Fig. 3c). However, the strength of the grazing impact was much stronger in the spring 
than in the summer (d.f. $=1, \chi^{2}=16.61, P<0.0001$ ) (Fig. 3d). Although plants were much larger and taller in the summer than in the spring (this reflects their sizes naturally), rate of plant leaf loss to grazing did not vary significantly with season (d.f. $=1,18, F=2.80, P=0.11$ ) (Appendix S1: Fig. S3). Replicating the spring vs. summer experiments in 2018 showed consistent results. The strength of the grazing impact was much stronger in the spring than in the summer (d.f. $=1, \chi^{2}=11.24, P=$ 0.0008 ), with crabs killing, on average, $9.47 \pm 0.36 \%$ of plants per day in the spring but only $2.00 \pm 1.10 \%$ of plants per day in the summer.

\section{Seasonal variation: Season-long effects}

Experiments lasting the entire spring and summer seasons, respectively, consistently demonstrated that the impact of grazing on plant survival was far stronger in spring than in summer (d.f. $=1, \chi^{2}=8.41, P=0.0037$ ) (Fig. 4a). In the spring experiment where plants were exposed to grazing in May and June, while plants in grazing exclusion treatments thrived, those in control treatments open to grazing nearly completely vanished. By contrast, in the summer experiment where plants once protected from grazing in the spring were released to grazing in July and August, although the impact of grazing on plant survival was also significant (d.f. $=1, \chi^{2}=5.33, P=0.0209$ ), a considerable number of plants survived in control treatments open to grazing (Fig. 4b). At the end of the summer experiment, plant biomass in control treatments was also significantly lower than in grazing exclusion treatments (d.f. $=1,6, F=60.45, P=0.0002$ ) (Fig. S4a), though plant survivors were 
generally larger and had much higher biomass in control treatments than in grazing exclusion

treatments (d.f. $=1,6, F=10.51, P=0.0177$ ) (Appendix S1: Fig. S4b).

\section{DISCUSSION}

Although the impacts of climate change on ecosystems have been widely documented,

great uncertainties exist and we lack a better understanding of the impacts of increasing weather variation under climate change (Thompson et al. 2013, Garcia et al. 2014). Our results show that the recovery and thus resilience of vegetation in a salt marsh was strongly affected by fluctuations in weather in the generally dry, spring season, which triggered aggregated grazing pressure on plants reestablishing in die-off areas. The impact of grazing was strongest in cool, wet days immediately following rain and was often insignificant in hot, dry periods. Furthermore, the cumulative impact of grazing across the generally dry, spring season was so critical that it quickly eliminated plant seedlings that could otherwise have become tolerant of grazing in the following summer (see Appendix S1: Fig. S5 for a conceptual model). These results not only provide clear evidence that weather fluctuations can strongly modulate the top-down impact of consumers on vegetation recovery, but can also help explain paradoxes in current understanding of variation in top-down control with mean climate at seasonal and annual scales.

Our study, firstly, exemplifies how the impact of consumers on vegetation can vary with fluctuations in weather at fine timescales. Our finding that grazing by crabs more strongly suppresses plant survival in days immediately following rain than in dry periods is in broad 
agreement with past studies (Alberti et al. 2007, He et al. 2015, He and Silliman 2016) showing that top-down control of plants by crab grazing is stronger in high-precipitation than in low-precipitation treatments or sites. The strength of grazing effect, however, also decreases with increasing temperature, likely because crab activity is reduced when heat stress increases (Bortolus et al. 2002, Altieri et al. 2010). We found an insignificant relationship between the strength of grazing effect and relative humidity, but relative humidity was generally high (50-80\%) across the study period.

Furthermore, grazing did not significantly affect plant survival when it was raining, likely because raining disturbed crab foraging activity. Rapid changes in grazing over short periods of different weather conditions are not surprising, as salt marsh crabs, as well as many other consumers, are known to be highly responsive to weather conditions (Bertness 1981, Sanford 2002). We encourage further tests of those mechanisms in experimental manipulations of weather variables when possible, and in this paper we mainly aimed to use natural rain events to examine variation in grazing impact with weather in real-world settings.

Our study further illustrates how variation in top-down control with fine-timescale fluctuations in weather can help explain paradoxes in current understanding of variation in top-down control with mean climate observed at broader timescales. Our work showed that crab grazing was so critical in the generally dry, spring season that it eliminated plant survival and the potential for vegetation to recover in die-off areas, while its impact was much weaker in the wet, summer season. Although it is known that the strength of top-down control varies with season in many ecosystems and can be especially strong in dry or spring seasons (Boyer et al. 2003, Veblen et al. 2008), our finding is in apparent contrast to studies suggesting that crab grazing is more intense 
in high-precipitation than in low-precipitation treatments or sites (Alberti et al. 2007, He et al. 2015).

This paradox can be explained by variation in grazing with fine-timescale weather fluctuations. Our study suggests that while crab grazing was largely inactive in the generally dry, spring season, intense grazing in cool, wet days had a cumulative impact that eliminated the potential of plant reestablishment in vegetation die-off areas. It should be noted that the predominant impact of grazing in spring rather than in summer could have been influenced and exacerbated by other factors such as phenological differences. Indeed, the dry, spring is a time when immature plant seedlings are often poor tolerators of herbivory (Strauss and Agrawal 1999). In the following wet, summer season, by contrast, although crab grazing continued, a significant number of plants can survive grazing, likely due to larger plant sizes (Appendix S1: Fig. S3a) and higher tolerances to grazing.

Understanding variation in top-down control with fluctuations in weather can also provide insight into variation in top-down control among years of varying mean climate. Our previous multi-year study, for example, found the impact of crab grazing to be stronger in drought years than in normal years (He et al. 2017), which is unexpected from the perspective that crab activities should be restricted by decreased precipitation (Alberti et al. 2007, He and Silliman 2016). Our present findings suggest that a relatively few number of scattered rain events or wet days during the overall drought period could have allowed intense grazing to kill all drought-stressed vegetation that were particularly susceptible to grazing pressure once it occurred. Whether the impact of grazers on vegetation die-off during droughts in other ecosystems (Jactel et al. 2012, He et al. 2017) is similarly modulated by fine-timescale fluctuations in weather still needs to be examined. In the case of snail 
grazing-driven salt marsh vegetation die-off in southeastern US during the 1999-2001 drought

(Silliman et al. 2005), periwinkle snails were highly sensitive to thermal stress and desiccation. These stresses are often exacerbated during hot, dry days or periods of drought. It is thus likely that their intense grazing on drought-stressed plants may have mainly concentrated in cool, wet periods or flooded periods over the multi-year drought. These perspectives on the role of fine-timescale variation in top-down control, however, cannot be gained by comparing sites or treatments that constantly differ in mean climate or in a physical stressor (e.g., salinity) associated with climate. Variation in top-down control with fluctuations in weather is likely common in many ecosystems. Our finding on weather modulation of the impact of grazing on salt marsh plants broadly agrees with previous studies on top-down control of prey by predators. Fluctuations in weather (e.g., storms, droughts or temperature over short periods), for example, have been shown to dictate variation in the impacts of predation by large vertebrate consumers on nest survival (Bowen and Janzen 2005, Skagen and Adams 2012), by ants and wasps in tropical forests (Touchon and Warkentin 2009), and also in many pelagic systems (e.g., Psenner and Sommaruga 1992, Hoover et al. 2006). Whether fine- or broad-timescale variation in climate can better predict top-down control, as well as other ecological processes, may differ among species (Hallett et al. 2004, Touchon and Warkentin 2009). Variation in top-down control with fine-timescale fluctuations in weather may be more remarkable when either one or both herbivores and plants (or predators and prey) are responsive to weather fluctuations.

This article is protected by copyright. All rights reserved. 
In conclusion, our study reveals that fluctuations in weather can strongly affect the impact of consumers on vegetation recovery following a catastrophic die-off associated with drought, and highlights the potential importance of such fine-timescale variation in top-down control with weather in driving ecosystem changes that emerge at larger, seasonal and annual timescales. Our findings concur with the idea put forward by Hastings (2004); examination of short-term processes can be key to understanding long-term behavior in ecological systems. Intense consumption by consumers is a major driver of the loss of foundation species in many ecosystems (e.g., grasses, trees, and corals) in the face of drought and heat stresses associated with climate warming (Silliman et al. 2013, He et al. 2017). Given that climate change is projected to alter weather patterns, the impacts of weather fluctuations on top-down control should be incorporated into a better understanding of the impacts of climate change on ecosystems. Our work suggests that a multi-timescale perspective on top-down control that combines the impact of short-term fluctuations in weather and that of long-term variation in mean climate can not only help understand and predict ecosystem dynamics under an increasingly variable climate, but may also inform conservation strategies or recovery plans for ecosystems that are already lost to climate change.

\section{ACKNOWLEDGEMENTS}

Funding was provided by National Key Basic Research Program of China (2013CB430406), Key Project of National Natural Science Foundation of China (51639001), and National Science Foundation for Innovative Research Group (51121003). Q.H. was partly supported by the Edward Stolarz Foundation.

This article is protected by copyright. All rights reserved. 


\section{LITERATURE CITED}

Alberti, J., A. Méndez Casariego, P. Daleo, E. Fanjul, B. Silliman, M. Bertness, and O. Iribarne. 2010. Abiotic stress mediates top-down and bottom-up control in a Southwestern Atlantic salt marsh. Oecologia 163:181-191.

Alberti, J., D. Montemayor, F. Álvarez, A. M. Casariego, T. Luppi, A. Canepuccia, J. P. Isacch, and O. Iribarne. 2007. Changes in rainfall pattern affect crab herbivory rates in a SW Atlantic salt marsh. Journal of Experimental Marine Biology and Ecology 353:126-133.

Altieri, A. H., B. K. van Wesenbeeck, M. D. Bertness, and B. R. Silliman. 2010. Facilitation cascade drives positive relationship between native biodiversity and invasion success. Ecology 91:1269-1275.

Anderegg, W. R. L., L. Plavcová, L. D. L. Anderegg, U. G. Hacke, J. A. Berry, and C. B. Field. 2013. Drought's legacy: multiyear hydraulic deterioration underlies widespread aspen forest die-off and portends increased future risk. Global Change Biology 19:1188-1196.

Angelini, C., and B. R. Silliman. 2012. Patch size-dependent community recovery after massive disturbance. Ecology 93:101-110.

Bertness, M. D. 1981. Predation, physical stress, and the organization of a tropical rocky intertidal hermit crab community. Ecology 62:411-425.

Borenstein, M., L. V. Hedges, J. P. Higgins, and H. R. Rothstein. 2009. Introduction to Meta-Analysis. John Wiley \& Sons, Chichester.

This article is protected by copyright. All rights reserved. 
Bortolus, A., E. Schwindt, and O. Iribarne. 2002. Positive plant-animal interactions in the high marsh of an Argentinean coastal lagoon. Ecology 83:733-742.

Bowen, K. D., and F. J. Janzen. 2005. Rainfall and depredation of nests of the painted turtle, Chrysemys picta. Journal of Herpetology 39:649-652.

Boyer, A. G., R. E. Swearingen, M. A. Blaha, C. T. Fortson, S. K. Gremillion, K. A. Osborn, and M. D. Moran. 2003. Seasonal variation in top-down and bottom-up processes in a grassland arthropod community. Oecologia 136:309-316.

Brown, G. P., and R. Shine. 2007. Rain, prey and predators: climatically driven shifts in frog abundance modify reproductive allometry in a tropical snake. Oecologia 154:361-368.

CaraDonna, P. J., W. K. Petry, R. M. Brennan, J. L. Cunningham, J. L. Bronstein, N. M. Waser, and N. J. Sanders. 2017. Interaction rewiring and the rapid turnover of plant-pollinator networks. Ecology Letters 20:385-394.

Carpenter, S. R., J. J. Cole, M. L. Pace, R. Batt, W. A. Brock, T. Cline, J. Coloso, J. R. Hodgson, J. F. Kitchell, D. A. Seekell, L. Smith, and B. Weidel. 2011. Early warnings of regime shifts: a whole-ecosystem experiment. Science 332:1079-1082.

Coumou, D., and S. Rahmstorf. 2012. A decade of weather extremes. Nature Climate Change 2:491-496.

This article is protected by copyright. All rights reserved. 
Gabler, C. A., M. J. Osland, J. B. Grace, C. L. Stagg, R. H. Day, S. B. Hartley, N. M. Enwright, A. S. From, M. L. McCoy, and J. L. McLeod. 2017. Macroclimatic change expected to transform coastal wetland ecosystems this century. Nature Climate Change 7:142-147.

Garcia, R. A., M. Cabeza, C. Rahbek, and M. B. Araujo. 2014. Multiple dimensions of climate change and their implications for biodiversity. Science 344:1247579.

Greenville, A. C., G. M. Wardle, and C. R. Dickman. 2012. Extreme climatic events drive mammal irruptions: regression analysis of 100 -year trends in desert rainfall and temperature. Ecology and Evolution 2:2645-2658.

Hallett, T. B., T. Coulson, J. G. Pilkington, T. H. Clutton-Brock, J. M. Pemberton, and B. T. Grenfell. 2004. Why large-scale climate indices seem to predict ecological processes better than local weather. Nature 430:71-75.

Hastings, A. 2004. Transients: the key to long-term ecological understanding? Trends in Ecology and Evolution 19:39-45.

He, Q., A. H. Altieri, and B. Cui. 2015. Herbivory drives zonation of stress tolerant marsh plants. Ecology 96:1318-1328.

He, Q., and B. R. Silliman. 2015. Biogeographic consequences of nutrient enrichment for plant-herbivore interactions in coastal wetlands. Ecology Letters 18:462-471.

He, Q., and B. R. Silliman. 2016. Consumer control as a common driver of coastal vegetation worldwide. Ecological Monographs 86:278-294.

This article is protected by copyright. All rights reserved. 
He, Q., B. R. Silliman, Z. Liu, and B. Cui. 2017. Natural enemies govern ecosystem resilience in the face of extreme droughts. Ecology Letters 20:194-201.

Hoover, R. S., D. Hoover, M. Miller, M. R. Landry, E. H. De Carlo, and F. T. Mackenzie. 2006.

Zooplankton response to storm runoff in a tropical estuary: bottom up and top down controls. Marine Ecology Progress Series 318:187-201.

Hubbard, K. G. 1994. Spatial variability of daily weather variables in the high plains of the USA. Agricultural and Forest Meteorology 68:29-41.

Jactel, H., J. Petit, M. L. Desprez-Loustau, et al. 2012. Drought effects on damage by forest insects and pathogens: a meta-analysis. Global Change Biology 18:267-276.

Li, S., G. Wang, W. Deng, Y. Hu, and W. W. Hu. 2009. Influence of hydrology process on wetland landscape pattern: A case study in the Yellow River Delta. Ecological Engineering 35: $1719-1726$.

Lovelock, C. E., I. C. Feller, R. Reef, S. Hickey, and M. C. Ball. 2017. Mangrove dieback during fluctuating sea levels. Scientific Reports 7: 1680.

McDowell, N. G., D. J. Beerling, D. D. Breshears, R. A. Fisher, K. F. Raffa, and M. Stitt. 2011. The interdependence of mechanisms underlying climate-driven vegetation mortality. Trends in Ecology and Evolution 26:523-532.

Osland, M. J., N. Enwright, and C. L. Stagg. 2014. Freshwater availability and coastal wetland foundation species: ecological transitions along a rainfall gradient. Ecology 95:2789-2802.

This article is protected by copyright. All rights reserved. 
Pascual, J., A. D. Canepuccia, J. Alberti, P. Daleo, and O. Iribarne. 2015. Rainfall intensity modulates the interaction between the marsh cordgrass Spartina densiflora and the mouse Akodon azarae. Marine Ecology Progress Series 523:71-80.

Psenner, R., and R. Sommaruga. 1992. Are rapid changes in bacterial biomass caused by shifts from top-down to bottom-up control? Limnology and Oceanography 37:1092-1100.

Sanford, E. 2002. Water temperature, predation, and the neglected role of physiological rate in rocky intertidal communities. Integrative and Comparative Biology 42:881-891

Scheffer, M., J. Bascompte, W. A. Brock, V. Brovkin, S. R. Carpenter, V. Dakos, et al. 2009. Early-warning signals for critical transitions. Nature 461:53-59.

Silliman, B. R., J. van de Koppel, M. D. Bertness, L. E. Stanton, and I. A. Mendelssohn. 2005. Drought, snails, and large-scale die-off of southern US salt marshes. Science 310:1803-1806.

Silliman, B. R., M. W. McCoy, C. Angelini, R. D. Holt, J. N. Griffin, and J. van de Koppel. 2013. Consumer fronts, global change, and runaway collapse in ecosystems. Annual Review of Ecology, Evolution, and Systematics 44:503-538.

Skagen, S. K., and A. A. Y. Adams. 2012. Weather effects on avian breeding performance and implications of climate change. Ecological Applications 22:1131-1145.

Strauss, S. Y., and A. A. Agrawal. 1999. The ecology and evolution of plant tolerance to herbivory. Trends in Ecology and Evolution 14:179-185.

This article is protected by copyright. All rights reserved. 
Suding, K. N., K. L. Gross, and G. R. Houseman. 2004. Alternative states and positive feedbacks in restoration ecology. Trends in Ecology and Evolution 19:46-53.

Thompson, R. M., J. Beardall, J. Beringer, M. Grace, and P. Sardina. 2013. Means and extremes: building variability into community-level climate change experiments. Ecology Letters 16:799-806.

Touchon, J. C., and K. M. Warkentin. 2009. Negative synergism of rainfall patterns and predators affects frog egg survival. Journal of Animal Ecology 78:715-723.

van Nes, E. H., and M. Scheffer. 2007. Slow recovery from perturbations as a genetic indicator of a nearby catastrophic shift. American Naturalist 169:738-747.

Veblen, K. E. 2008. Season- and herbivore-dependent competition and facilitation in a semiarid savanna. Ecology 89:1532-1540.

Wolkovich, E. M., B. I. Cook, K. K. Mclauchlan, and T. J. Davies. 2014. Temporal ecology in the Anthropocene. Ecology Letters 17:1365-1379.

Wright, A., S. A. Schnitzer, and P. B. Reich. 2015. Daily environmental conditions determine the competition-facilitation balance for plant water status. Journal of Ecology 103:648-656.

This article is protected by copyright. All rights reserved. 


\section{Data AvailabiLity}

Data are available from Zenodo: http://doi.org/10.5281/zenodo.1471257

\section{FIGURE LEGENDS}

Figure 1 Photographs of the study site. This salt marsh ecosystem experienced an intensive vegetation die-off following a severe drought in 2011. (a) The study site in August 2013; (b) Limited natural recruitment grazed by crabs, a prominent consumer in many coastal habitats.

Figure 2 Daily weather conditions over the study period in 2013. (a) Daily rainfall (and periods of different experiments), and (b) daily mean temperature and relative humidity.

Figure 3 Impacts of grazing on plant survival in the weather and short-term seasonal experiments. Data (means $+\mathrm{SE} ; n=10$ ) are relative increases in plant mortality in grazing treatments vs. permanent grazing exclusion treatments. (a) Weather experiments; (b) short-term experiment in the spring season; (c) short-term experiment in the summer season; and (d) comparison of daily-averaged grazing effect between spring and summer. In (a), within each bar category, bars sharing a letter are not significantly different from one another $(P>0.08)$. In $(\mathrm{b}$ and $\mathrm{c})$, bars having a star indicate significant effects of grazing on plant mortality. NS indicates not significant. In (d), statistical differences are indicated with a $P$ value.

This article is protected by copyright. All rights reserved. 
Figure 4 Impacts of season-long grazing on plant survival in spring vs. summer seasons. (a)

Relative differences in the number of plants in control treatments vs. grazing exclusion treatments, and (b) number of plants in control and grazing exclusion treatments. Data are means ( $+\mathrm{SE} ; n=8)$. Statistical differences between spring and summer (a) and between control and grazing exclusion treatments (b) are indicated with $P$ values.

This article is protected by copyright. All rights reserved. 

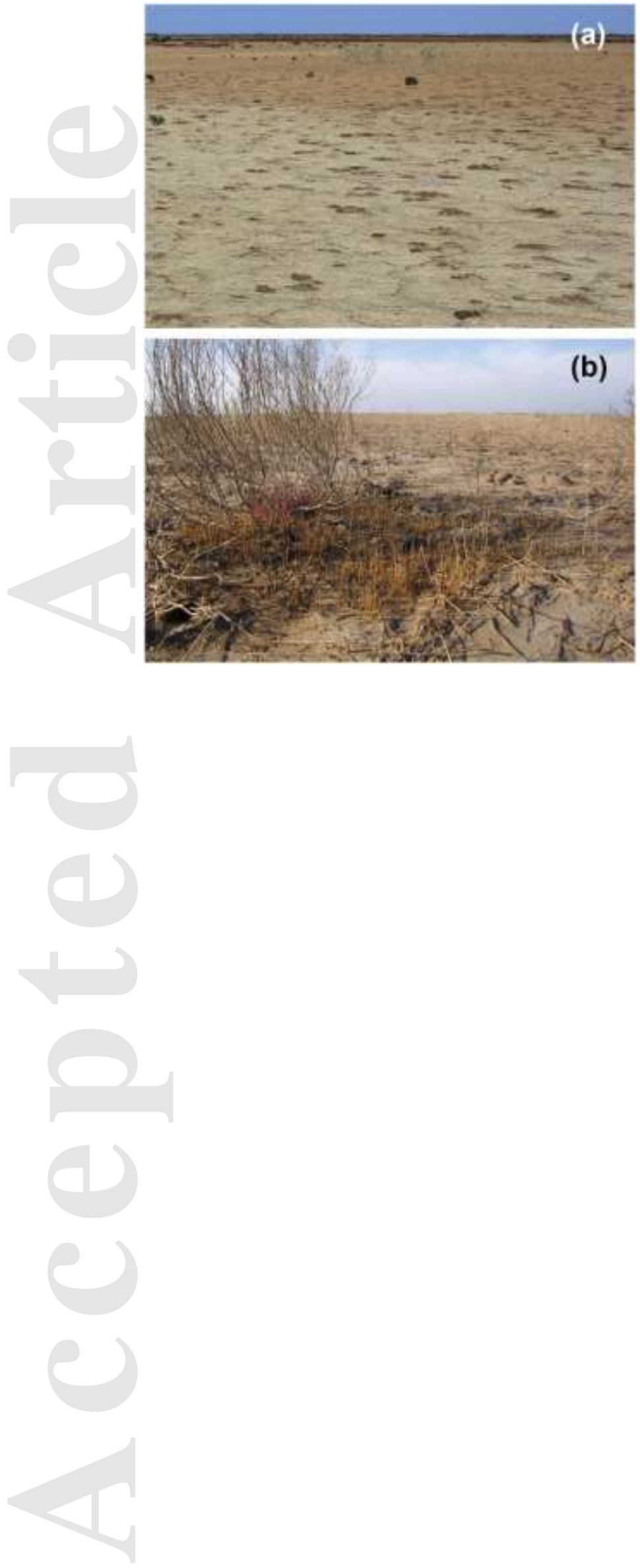

This article is protected by copyright. All rights reserved. 

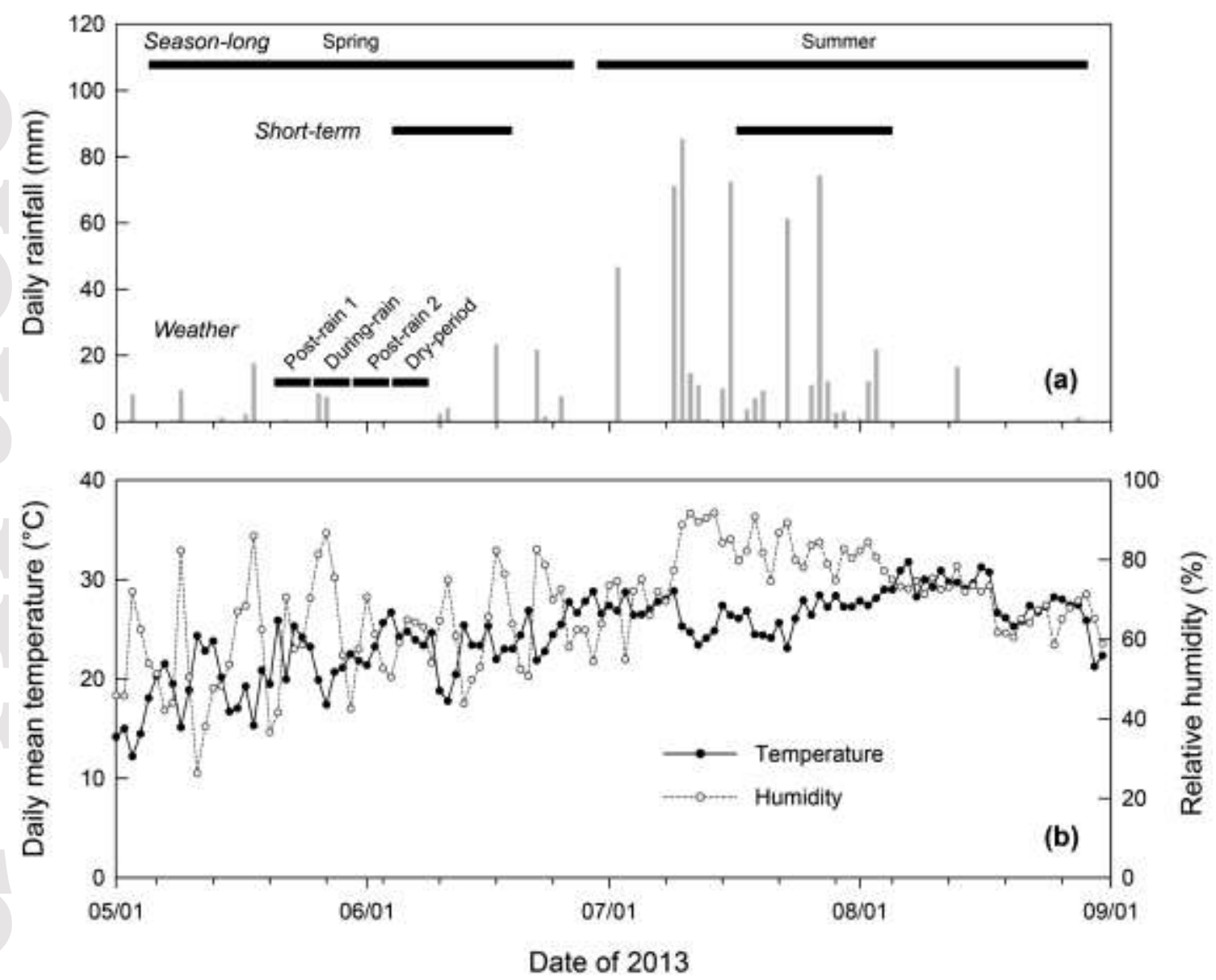

This article is protected by copyright. All rights reserved. 

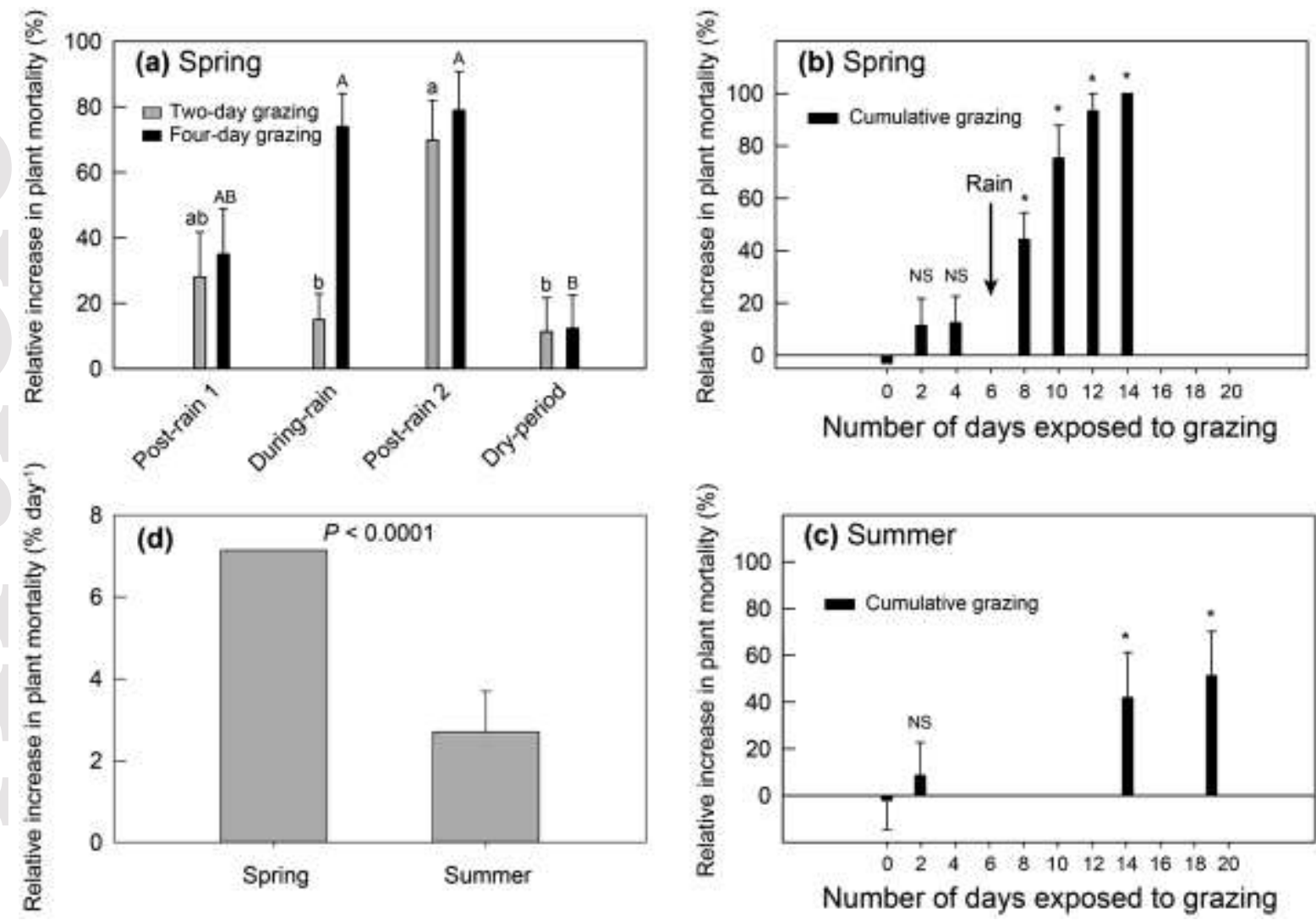

This article is protected by copyright. All rights reserved. 

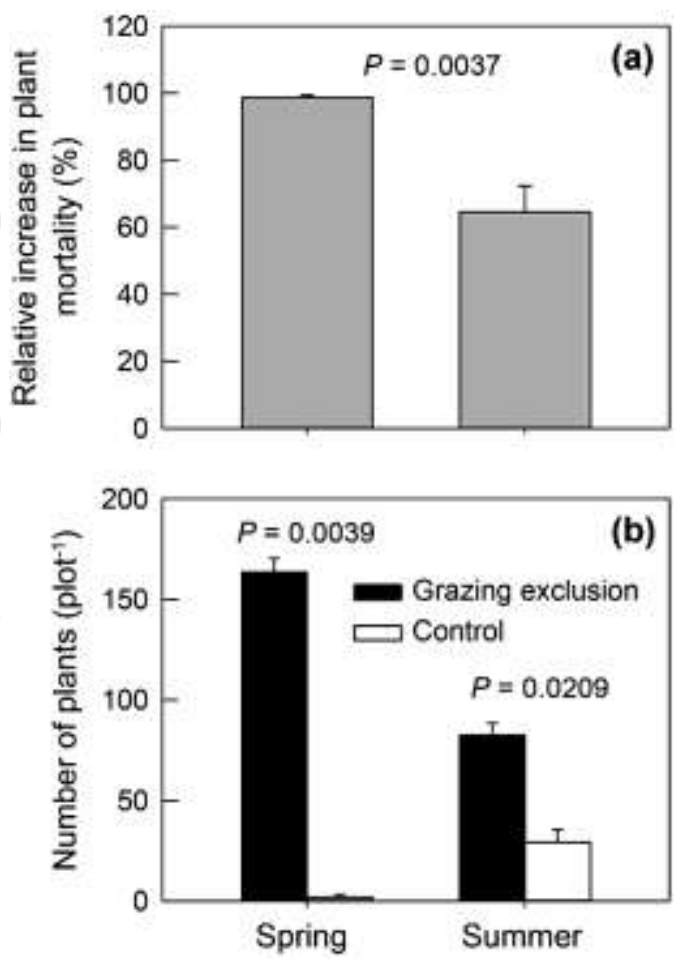

This article is protected by copyright. All rights reserved. 